\title{
Atom Probe Tomography Study of In-doped ZnO
}

\author{
Mor Baram ${ }^{1}$, Xin Liang ${ }^{1}$ and David R. Clarke ${ }^{1}$ \\ 1. School of Engineering and Applied Sciences, Harvard University, Cambridge MA USA.
}

In-doped $\mathrm{ZnO}$ is a highly promising material for thermoelectric (TE) applications. In contrast to other materials purposed for that application (i.e $\mathrm{Si}-\mathrm{Ge}$ alloys, transition metal disilicides, and B-based compounds), the $\mathrm{In}_{2} \mathrm{O}_{3}(\mathrm{ZnO})_{\mathrm{k}}$ structure (where $\mathrm{k}$ is an integer) possess several unique advantages. It has high chemical and structural stability at high temperatures, a wide band gap which prevents thermal excitation of carriers and hence allows the figure of merit, ZT, increase with temperature. In addition, the In-doped $\mathrm{ZnO}$ forms compositionally dependent superlattice which sometime referred to as homologous series. The superlattice structure creates phonon scattering interfaces which offer additional mechanism for the reduction of the thermal conductivity.

The unique structure of $\operatorname{In}_{2} \mathrm{O}_{3}(\mathrm{ZnO})_{\mathrm{k}}$ has been the focus of numerous studies. X-ray diffraction, Transmission Electron Microscopy (TEM) and Scanning TEM have shown before the existence of polytypoid structure of $\mathrm{ZnO}$ wurtzite slabs separated by single octahedrally-coordinated $\mathrm{InO}_{2}$ sheets lying on the basal plane, while the spacing depends on composition [1]. In addition, another structure of "Zig-Zag" was found to exist in the system [2]. However, the concentration and distribution of the In atoms in the $\mathrm{ZnO}$ slabs still remain unclear. A control on the In inside the $\mathrm{ZnO}$ slabs, can contribute to the thermal, optical and electrical properties of the material and therefore is much of an interest.

In this study, we have used Atom Probe Tomography (APT) in order to analyze the composition profile of $\mathrm{In}_{2} \mathrm{O}_{3}(\mathrm{ZnO})_{\mathrm{k}}$ structure. First, In-doped $\mathrm{ZnO}$ samples were prepared using commercial high purity nitrate powders, $\mathrm{Zn}\left(\mathrm{NO}_{3}\right)$ and $\mathrm{In}\left(\mathrm{NO}_{3}\right)_{3}$ by molecular mixing with organic materials and combustion process, followed by calcination, densification (using current assisted system) and post-annealing. Then APT tips were prepared from the annealed $\left(\mathrm{Zn}_{1-\mathrm{x}} \mathrm{In}_{\mathrm{x}}\right) \mathrm{O}(\mathrm{x}=0.1)$ using a Focused Ion Beam Scanning Electron Microscope (FIB-SEM) [3]. The tips were then studied using laser pulse Local Electrode Atom Probe (LEAP) system.

Three different configurations of the materials were observed from the APT measurements. A complete random distribution of $\mathrm{In}, \mathrm{Zn}$ and Oxygen, a superlattice structure of $\mathrm{In} / \mathrm{ZnO}$ slabs separated by Indium Oxide sheets and a "Zig-Zag" Structure as can be seen in Fig. 1. The reconstruction and composition analysis of the different structures provide the information on the distribution of the In inside the $\mathrm{ZnO}$ slabs and in the sheets.

In this work, we demonstrate the preparation and the analysis of atom probe tips from bulk In-doped $\mathrm{ZnO}$. The APT provides chemical and structural analysis of the system which was compared with previous TEM results and the different models of the superlattice structure. In addition, a correlation with of the APT results and the thermal conductivity was done. 


\section{References:}

[1] Y Yan, S J Pennycook, J Dai, R P H Chang, A Wang and T J Marks, Applied Physics Letters, 73(18), (1998), p. 2585.

[2] C Ii, Y Bando, M Nakamura, and N Kimizuka, Journal of Electron Microscopy 46(2) (1997), p. 119.

[3] M K Miller, K F Russell, K Thompson, R Alvis, and D J Larson, Microscopy and microanalysis 13(6) (2007), p. 428.

[4] The authors would like to thank E. Marquis, M. Bachhav and A. Hunter for their assistance with the FIB and APT work and fruitful discussions and D.C. Bell for his help with the APT.
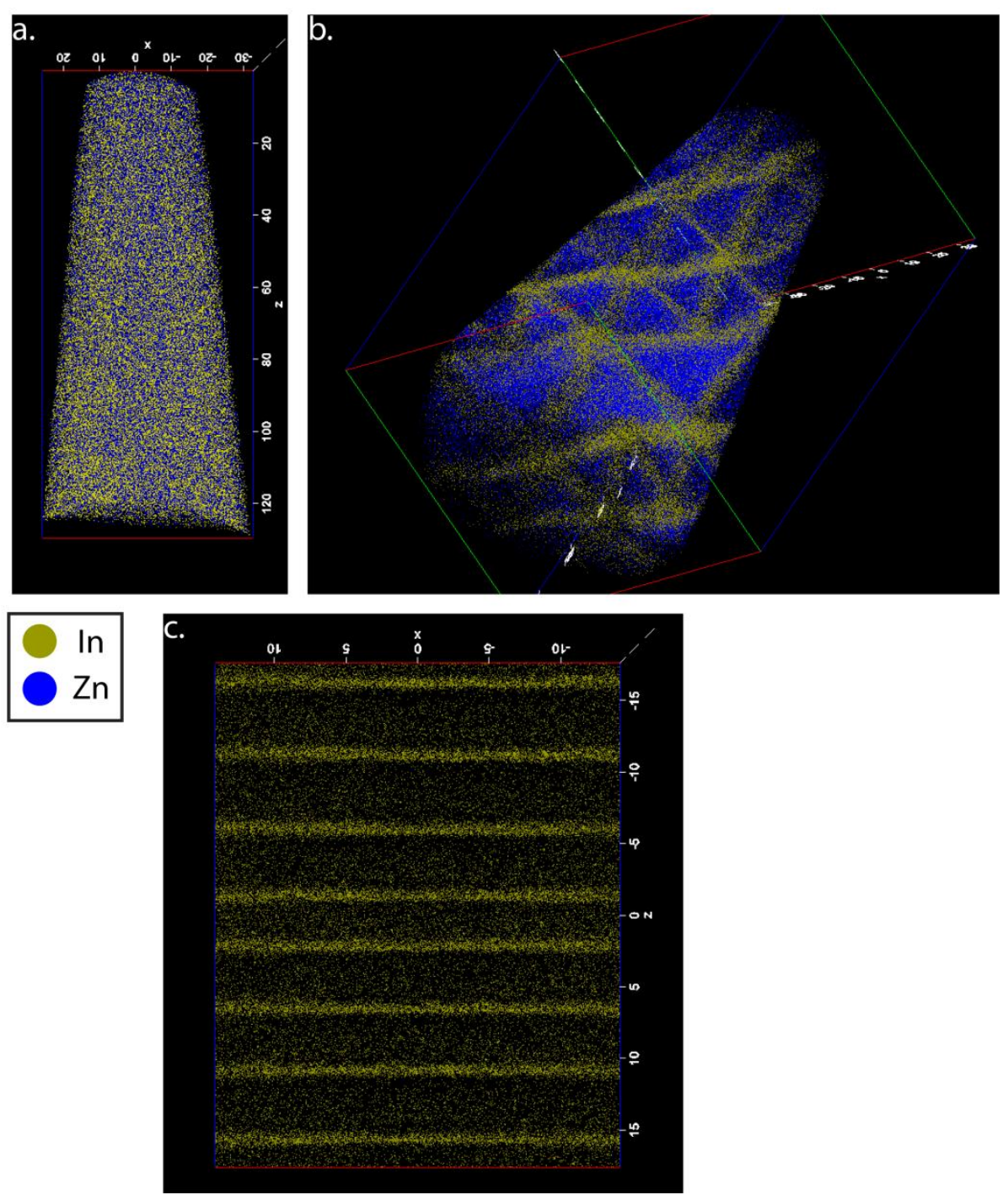

Figure 1. Three different configurations of the $\mathrm{In} / \mathrm{ZnO}$ structure a. Completely random distribution of In, Zn b. In and Zn in a"Zig Zag" Structure and c. Distribution of Indium in a superlattice structure of Indium Oxide sheets between $\mathrm{ZnO}$ slabs. 